\title{
Extracellular Matrix Modulates Morphology, Growth, Oxidative Stress Response and Functionality of Human Skin Fibroblasts during Aging In Vitro
}

Peter Joergensen and Suresh I.S. Rattan

Department of Molecular Biology and Genetics, Laboratory of Cellular Ageing, Aarhus University, Denmark

*Corresponding author: Suresh I.S. Rattan, Department of Molecular Biology and Genetics, Laboratory of Cellular Ageing, Aarhus University, Denmark, Tel: 28992496; E-mail: sisr@mb.au.dk

Rec date: May 02, 2014, Acc date: May 27, 2014, Pub date: June 02, 2014

Copyright: () 2014 Joergensen P, et al. This is an open-access article distributed under the terms of the Creative Commons Attribution License, which permits unrestricted use, distribution, and reproduction in any medium, provided the original author and source are credited.

\begin{abstract}
The Hayflick system of cellular aging and replicative senescence in vitro has been used widely in both basic and applied research in bio gerontology. The state of replicative senescence is generally considered to be irreversible, but is modifiable by genetic and environmental manipulations. Some recent observations indicate that replicative lifespan, senescence and functionality of cells in vitro can be significantly affected by the quality of the extra cellular matrix (ECM). Following up on those reports, here we show that using the ECM prepared from early passage young cells, partial rejuvenation of serially passaged human facial skin fibroblasts was possible in pre-senescent middleaged cells, but not in fully senescent late passage cells. ECM from young cells improved the appearance, viability, stress tolerance and wound healing ability of skin fibroblasts. Furthermore, young ECM modulated the oxidative stress response transcription factor Nrf-2 and its downstream effector haem-oxygenase (HO-1), possibly through the amelioration of the environmental stress induced by the plastic surface of the culturing flasks. Therefore, it is important to consider the role of ECM in modulating the response of cells both for mechanistic understanding of cellular senescence and while testing for potential aging interventions.
\end{abstract}

Keywords: Matrix; Human; Skin; Stress; Longevity

\section{Introduction}

The Hayflick phenomenon of cellular aging and replicative senescence observed in serially passaged normal diploid differentiated cells is a well-studied phenomenon for more than 50 years, and it has had a profound impact on the elucidation of the molecular basis of aging [1]. The Hayflick system of serially passaged-related cellular aging and the ultimate replicative senescence has also been widely used to test the effects of various natural and synthetic compounds as modulators of aging and longevity, and as rejuvenators of senescent cells [2-5]. However, one of the studies has reported that a simple shift of senescent fibroblasts on to the extra cellular matrix (ECM) produced by early passage young fibroblasts completely rejuvenated the senescent cells in terms of morphology, proliferation and several other characteristics [6]. These observations fitted well with the understanding that the microenvironment surrounding the cells has a profound effect on cellular function and fate in vitro.

The effects of the microenvironment are determined by soluble factors as well as by the network of fibers and macromolecules constituting the ECM surrounding the cell. ECM is mainly composed of a three-dimensional scaffold of collagen, intertwined with proteoglycans and glycoproteins, which have an intrinsic property to self-associate and to form ordered assemblies with other ECM proteins, and rarely function as isolated soluble molecules [7]. ECM not only provides structural support for the cells and tissues of the body as some biological mute bystander, but performs varied rolls, such as promoting cell signaling and function, promoting or impeding cellular migration, and acting as a reservoir for growth factors, enzymes, cytokines and other diffusible molecules [8]. Lately, it has been recognized that these properties have a significant influence on cell behavior and development, most clearly seen in stem cells [9].

The effects of the microenvironment on cells have been shown to extend to aging. For example, it has been demonstrated that the bloodborne factors from young mice can rejuvenate aging stem cells from old mice [10]. Several other studies, using in vitro produced ECM, have shown that cells grown on such a substrate can be maintained for a longer time before growth arrest $[11,12]$, can maintain stemness for a longer duration $[13,14]$, and can improve several other functional aspects, such as restoration of osteogenesis by aged mesenchymal stem cells [15-17]. Importantly, it has been highlighted that this effect is dependent on the age of the cells producing the ECM, with ECM derived from old cells being of an inferior quality [15]. Together, these results point to the ECM, and hence the local cellular environment, as being a critical factor in determining the functionality and longevity of cells.

The aim of this study is to follow up on a previously published report that ECM from early passage young fibroblasts can fully rejuvenate senescent cells [6]. In addition, this study aims to elucidate the molecular basis for the effects of ECM on serially passaged human skin fibroblasts undergoing aging in vitro, especially with respect to the activation of the oxidative stress response marker, transcription factor Nrf-2.

\section{Materials and Methods}

\section{Cell culture}

A normal diploid fibroblast cell strain, designated FSF-1, derived from the facial skin (eyelid) of a healthy middle-aged woman, was used in these studies [18]. Cells were grown in T75 $\left(75 \mathrm{~cm}^{2}\right)$ or T25 $(25$ $\mathrm{cm}^{2}$ ) plastic tissue culture flasks (Sarstedt, Germany) using complete 
media composed of Dulbecco's Minimum Essential Medium (DMEM), containing L-glutamine, and supplemented with $10 \%$ foetal calf serum (FCS; Biological Industries, Beit Haemek, Israel) and 100 $\mathrm{U} / \mathrm{ml}$ penicillin and streptomycin (Biowhittaker), and were incubated at $37^{\circ} \mathrm{C}, 5 \% \mathrm{CO}_{2}$ and $95 \%$ humidity. Subculturing was performed when cells were near confluent (90-95\% confluency) by first washing the cells with PBS, and then harvesting them using a $0.25 \%$ trypsin/ EDTA solution for $5 \mathrm{~min}$. Cell cultures were split at 1:2 or 1:4 ratio in new flasks, thus adding 1 or 2 passages $(\mathrm{P})$ to their age, respectively. Cell numbers were determined using the Countess automated cell counter (Invitrogen, Eugene, Oregon, USA). At least two independent readings were taken for cell numbers. Serially passaged FSF-1 had a proliferative lifespan of up to $\mathrm{P} 65$, and was divided into three age groups: young FSF-1 (Y-FSF; P<22), middle-aged FSF-1 (M-FSF; P 22 to 52), and old or near senescent FSF-1 (O-FSF; P $>56$ ). Y-FSF used in this series of experiments varied between $\mathrm{P} 10$ and $\mathrm{P} 21, \mathrm{M}-\mathrm{FSF}$ varied between $\mathrm{P} 32$ and P 43, and O-FSF varied between P 57 and P 61 .

\section{ECM preparation}

Several different methods were used for the production and preparation of ECM from Y-FSF (Table 1). A common step for all these methods was that the cells were first seeded at a density of approximately 6,000 cells $/ \mathrm{cm}^{2}$ in appropriate plastic flasks or wells, and were then grown for different lengths of time, followed by the removal of the cells and preparation of the ECM. A crucial difference among various methods was the method of removal of cells either by enzymatic, chemical or physical methods (Table 1). The remaining ECM on the cell-free surface was then washed $3 \times 5 \mathrm{~min}$ in PBS before either being used for experiments immediately or storing it in the fridge $\left(4^{\circ} \mathrm{C}\right)$ in cold PBS supplemented with $100 \mathrm{U} / \mathrm{ml}$ penicillin and streptomycin. However, ECM was not stored for more than 4 weeks before being used, as preliminary tests had shown that the integrity of the ECM was affected negatively on a longer period of storage.

When trypsin, EDTA, or the mechanical technique was used, the leftover ECM was stored for at least 1 week before use, in order to avoid contamination with any ECM-producing cells. As two different production-times ( 3 days and 15 days) were used, these methods are referred to as "a" and "b", respectively (Table 1).

\begin{tabular}{|l|l|l|l|l|l|}
\hline $\begin{array}{l}\text { Method of } \\
\text { cell } \\
\text { removal }\end{array}$ & $\begin{array}{l}\text { 0.25\% } \\
\text { Trypsin/ } \\
\text { EDTA } \\
\text { (Enzymati } \\
\text { c) }\end{array}$ & $\begin{array}{l}1 \\
\text { EDTA } \\
\text { (Chemica } \\
\text { I) }\end{array}$ & $\begin{array}{l}\text { Cell-scraper } \\
\text { (Mechanical } \\
\text { ) }\end{array}$ & $\begin{array}{l}\text { 20 mM } \\
\text { NH4OH } \\
\text { and 0.5\% } \\
\text { Triton } \\
\text { X-100 } \\
\text { (Chemica } \\
\text { I) }\end{array}$ & $\begin{array}{l}\text { 0.5\% } \\
\text { Triton } \\
\text { X-100 } \\
\text { (Chemica } \\
\text { I) }\end{array}$ \\
\hline $\begin{array}{l}\text { Method } \\
\text { designation } \\
*\end{array}$ & $1 \mathrm{a}, 1 \mathrm{~b}$ & $2 \mathrm{a}, 2 \mathrm{~b}$ & $3 \mathrm{a}, 3 \mathrm{~b}$ & $4 \mathrm{a}, 4 \mathrm{~b}$ & $5 \mathrm{a}, 5 \mathrm{~b}$ \\
\hline $\begin{array}{l}\text { Time taken } \\
\text { for cell- } \\
\text { removal }\end{array}$ & 5 min & 30 min & - & 5 min & 30 min \\
\hline $\begin{array}{l}\text { Storage } \\
\text { time }\end{array}$ & $7-28$ days & $7-28$ days & $7-28$ days & $0-28$ days & $0-28$ days \\
\hline $\begin{array}{l}\text { Adapted } \\
\text { from }\end{array}$ & {$[6]$} & {$[6]$} & {$[29]$} & {$[15]$} & {$[11]$} \\
\hline
\end{tabular}

Table 1: Overview of different methods of preparation for ECM. ${ }^{*}$ Method designation refers to the number of days for ECM production as: $a=3$ days, and $b=15$ days

\section{Cell survival, size and stress induction}

Cells were seeded on a plain plastic surface or on prepared ECM, in either 96-well plates (TPP, Switzerland) at a cell-density of 15,000 cells $/ \mathrm{cm}^{2}$, or in T25 flasks at a cell-density of $5,000 \mathrm{cells} / \mathrm{cm}^{2}$. Cells were either seeded in 96-well plates or in T25 flasks and left for 3 days, prior to treatment with a stressor, such as glyoxal (Sigma).

For cell survival analysis, $25 \mu \mathrm{l}$ of $0.5 \mathrm{mg} / \mathrm{ml}$ MTT in PBS (Sigma, USA) was added to cells seeded in 96-well plates, which had been exposed to experiment-specific treatments. The cells with MTT were then left for another $5 \mathrm{hr}$ in the incubator at $37^{\circ} \mathrm{C}$. The media was then removed and a 1:1 solution of DMSO and isopropanol $(200 \mu \mathrm{l} /$ well $)$ was added to each well and aspirated a few times. Absorbance was measured using a micro plate reader model 550 (BIO-RAD) at 595 $\mathrm{nm}$, subtracting readings at $655 \mathrm{~nm}$.

For cell size and auto fluorescence analysis, cells were harvested by trypsinization and centrifuged at $300 \times \mathrm{g}$ for $5 \mathrm{~min}$ before resuspending in $1 \mathrm{ml}$ PBS for washing. The cells were again centrifuged and the cell-pellet was re-suspended in $1 \mathrm{ml}$ ice-cold PBS. The cellsamples were put on ice and transferred to the FACS-Calibur analyzer (bench flow cytometer) for analysis, and data were acquired using Cell Quest Pro. The analysis was carried out using Flowing software 2.5.0.

For the analysis of stress response induction, cells were harvested by scraping on ice and centrifuged at $700 \times \mathrm{g}$ for $5 \mathrm{~min}$, followed by lysis and protein quantification, using Plus One 2D Quant Kit (Amersham). After adding sample buffer (4x, BIO-RAD) and XT reducing agent $(20 \mathrm{x}, \mathrm{BIO}-\mathrm{RAD})$ the sample was boiled for $5 \mathrm{~min}$ before loading to the prefabricated $12 \%$ Bis-Tris SDS-PAGE gels (BIO-RAD). The gel was then transferred to a nitrocellulose membrane (BIO-RAD) for $90 \mathrm{~min}$ at 100 volts at $5^{\circ} \mathrm{C}$. After blocking in $4 \%$ skim milk the membrane was incubated with primary antibody followed by three washes with PBS and another three washes with $0.05 \%$ Tween-PBS before being incubated with secondary antibody. The membrane was treated with chemiluminescent ELC (GEHealthcare) before developing the film (Kodak Medical Film) in a dark room (AGFA Curix 60). Following antibodies were used: $\beta$-actin (AC-15, Sigma), Nrf-2 (H-300, Santa Cruz), HO-1 (Hsp32, Nordic Biosite), Rabbit-HRP (P0399, Dako) and Mouse-HRP (P0447, Dako).

\section{Wound healing assay}

A wound healing assay was performed, as previously described [19], with some modifications. Approximately 200,000 Y-FSF were seeded per well in 6-well plates (with or without Y-ECM) to form a 95-100\% confluent monolayer of cells. These cells were left to attach for $24 \mathrm{hr}$ before a wound was made with a modified cell-scraper. Phase contrast microscopic pictures were taken at 0,24 and $48 \mathrm{hr}$. The extent of wound healing was determined using Zeiss AxioVision V. 4.8.2.0, where the area not covered by cells was measured in pixels2 (manual outlining).

\section{Results and Discussion}

\section{ECM-induced morphological rejuvenation}

Our initial attempts at rejuvenating senescent cells to a youthful appearance by following the method 1 a (Table 1) did not result in a reversal of senescence. O-FSF were seeded and maintained for up to 21 days on the ECM produced by Y-FSF, but there was no significant improvement in either cellular morphology or proliferative rate of $\mathrm{O}$ - 
FSF during this period (Figure 1). However, there were clear-cut serially passage-related differences between the morphology of early passage young cells and late passage near senescent old cells, similar to the one reported in numerous publications on cellular senescence [1]. As compared with Y-FSF, O-FSF grown on plastic surface was highly enlarged, irregular, vacuolated and heterogeneous (Figure $1 \mathrm{~A}$ and $\mathrm{B}$ ). O-FSF grown for 21 days on the ECM prepared from Y-FSF appeared and behaved almost similar to the cells on the uncoated plastic surface (Figure 1C). Although there was thinning and elongation of some cells, generally this population of cells was very heterogeneous with large vacuolated cells spread around at random and in a nonproliferating condition (Figure 1C). There may be several reasons for our failure to replicate the results published previously [6], and these include differences between the cell strains in terms of the tissue origin, donor age, and laboratory variations in producing the ECM.
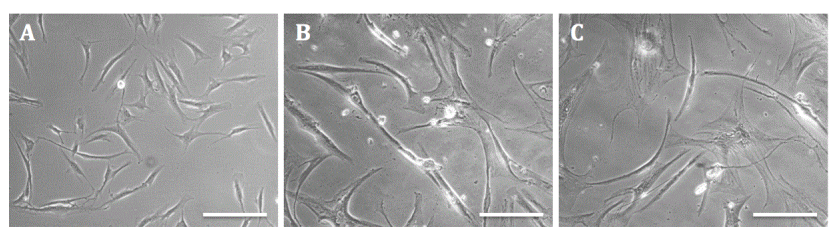

Figure 1: Morphology of FSF-1 cells grown on plastic or ECMcoated surface. (A) Early passage (P 17) young FSF (Y-FSF) grown for 3 days on uncoated plastic; (B) Late passage near-senescent ( $P$ 59) FSF (O-FSF) grown on uncoated plastic, and (C) O-FSF grown for 21 days on the ECM produced by Y-FSF, using the method 1a; phase contrast microscopic pictures using 10x objective lens; scale bar $=200 \mu \mathrm{m}$.

Therefore, we employed other methods for the preparation of ECM in 3 days (methods 1a to 5a; Table 1), for the senescent cells to be seeded on. However, this change to the setup did not change the outcome of the experiments significantly, showing no obvious changes in the morphology and the proliferative behavior of the senescent cells maintained for 21 days or longer.

We then increased the time for the production of ECM by young cells from 3 to 15 days (methods $1 \mathrm{~b}$ to $5 \mathrm{~b}$; Table 1 ), and the ECM thus produced was named trypsin-ECM, EDTA-ECM, scraped-ECM, YECM and triton-ECM, respectively. The effects of seeding Y-FSF on to a normal plastic surface or on to one of the above-mentioned ECM are shown in Figure 2. As compared with the plastic (Figure 2A), cells seeded on ECM, except trypsin-ECM (Figure 2B), performed better in terms of attachment and elongation within $3 \mathrm{hr}$ of seeding (Figure 2CF). In addition, a closer scrutiny of the populations of cells over time revealed that there was a visually less stressed morphology in terms of fewer granules and the general appearance. Importantly, methods $4 \mathrm{~b}$ and $5 \mathrm{~b}$ gave rise to visual ECM fibers (Figure $2 \mathrm{E}$ and $\mathrm{F}$ ), which determined the directionality of the seeded cells, with cells aligning along the length of the fibers. Moreover, the initial formation of several randomly oriented protrusions resulting in a very heterogeneous population of cells was reversed to a morphologically homogenous population of stretched slender cells within $24 \mathrm{hr}$, as the cells slowly aligned with the fibers. These morphological dissimilarities between ECM-seeded cells and the controls on uncoated plastic are similar to what others have previously reported [20]. However, these differences became diminished over time, possibly as a consequence of the control cells producing their own ECM and/or due to cell-cell interaction provided by an increased cell-density. Based on these observations, and the fact that a similarly produced ECM has recently been used and structurally investigated by others [17], method $4 \mathrm{~b}$ (henceforth designated as Y-ECM) was chosen as the method of choice to produce ECM for the rest of the experiments.

Having determined which method to use for the optimal production of ECM we resumed our rejuvenation-experiments, this time seeding both mid-passage M-FSF and late passage senescent $\mathrm{O}$ FSF on Y-ECM. Figure 3 shows the effects of culturing mid-passage and late passage cells on Y-ECM for 7 and 21 days, respectively. There was a significant improvement in the morphology of M-FSF seeded on Y-ECM as compared with those on the normal plastic surface (Figure $3 \mathrm{~A}$ and $\mathrm{B}$ ). M-FSF grown on Y-ECM became elongated, smaller and smoother, and produced a more homogenous pattern of alignment in whorls with the ECM fibers. This gradual change to the morphology seen in M-FSF on Y-ECM would take place over a period of 2-10 days, and would persist for at least 21 days with continual exposure to $\mathrm{Y}$ ECM.

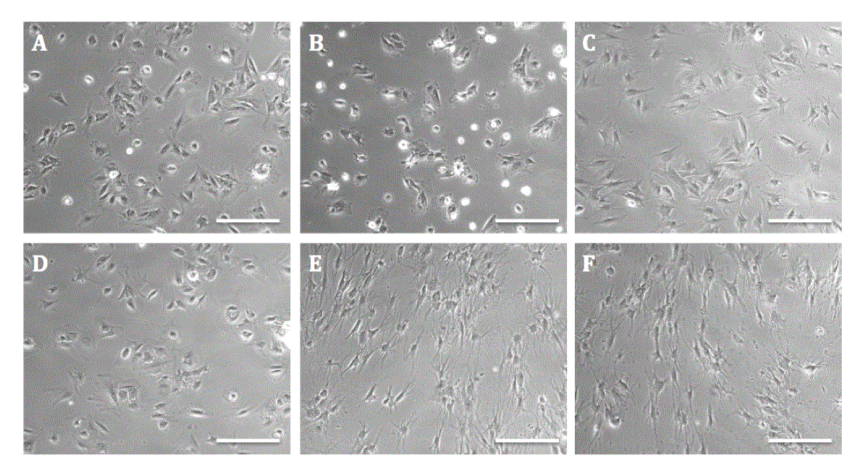

Figure 2: Morphology of early passage (P 19) Y-FSF cells $3 \mathrm{hr}$ after seeding on (A) plastic, (B) trypsin-ECM (method 1b), (C) EDTAECM (method 2b), (D) scraped-ECM (method 3b), (E) Y-ECM (method $4 \mathrm{~b}$ ), and $(\mathrm{F})$ triton-ECM (method $5 \mathrm{~b}$ ); phase-contrast microscopic pictures using 10x objective lens; scale bar $=200 \mu \mathrm{m}$

However, this rejuvenation was only partial and did not convert all cells to appear like early passage level cells. Moreover, reseeding of the rejuvenated M-FSF from Y-ECM back on to uncoated plastic would result in a reversal of the morphology in about a week. In comparison, O-FSF grown on Y-ECM did not show any significant changes in their appearance after 21 days of maintenance (Figure 3C and D), or even after a much longer period of maintenance for up to 100 days. Interestingly, similar to the behavior of Y-FSF on Y-ECM (Figure 2), both M-FSF and O-FSF attached relatively faster and formed more protrusions on Y-ECM as compared with those seeded on the plastic surface. However, only M-FSF would align with the ECM-fibers albeit more slowly than Y-FSF, whereas O-FSF seemingly moved around randomly degrading the ECM and leaving behind debris in the media, possibly a consequence of the higher expression of ECM degradation proteins seen in senescent cells [21]. Thus, there was clearly an agedependent response of FSF to ECM, with mid-passage cells better able to attach and respond to the ECM and able to become relatively more rejuvenated than the late-passage senescent cells.

Partial rejuvenation of M-FSF grown on Y-ECM for a 7-day period was also demonstrated by flow cytometric analysis, which measured the cell size, cell granularity indicating lysosomal residual bodies, and 
Citation: Joergensen P, Rattan SIS (2014) Extracellular Matrix Modulates Morphology, Growth, Oxidative Stress Response and Functionality of Human Skin Fibroblasts during Aging In Vitro. Aging Sci 2: 122. doi:10.4172/2329-8847.1000122

Page 4 of 7

auto fluorescence indicating the level of oxidative damaged macromolecules and protein-lipid conjugates. These parameters are well known to increase during cellular aging and a decrease in these characteristics can be an indicator of rejuvenation [1,22]. Figure 4 show that there was a significant decrease in the cell size, granularity and autofluorescence, with a general shift to the left in the cell population for these 3 characteristics. Parallel studies using methods $1 \mathrm{~b}-3 \mathrm{~b}$ and $5 \mathrm{~b}$ showed that a similar but less pronounced reduction to these characteristics could also be achieved using different ECMs.
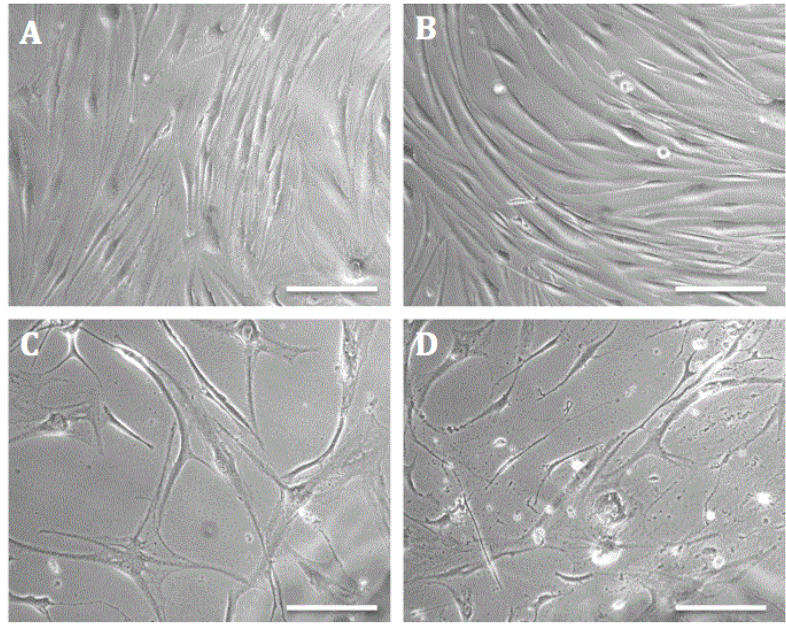

Figure 3: Partial rejuvenation of mid-passage, but not senescent, FSF seeded on Y-ECM. M-FSF (P 36) grown for 7 days on plastic (A) or on Y-ECM (B); and O-FSF (P 60) grown for 21 days on plastic (C) or on Y-ECM (D); phase-contrast microscopic pictures using 10x objective lens; scale bar $=200 \mu \mathrm{m}$.

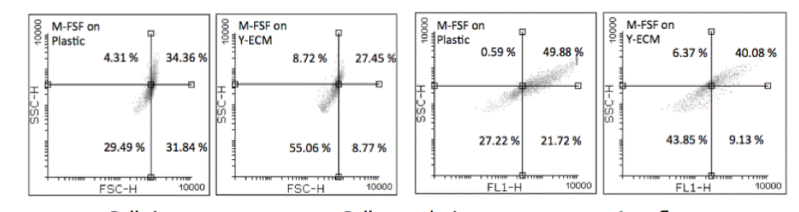

Cell size Cell granularity Autofluorescence

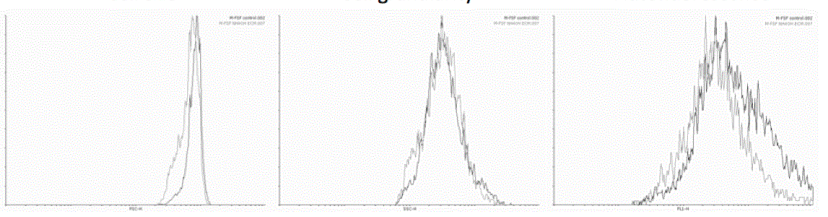

Figure 4: Flow cytometry analysis of mid-passage FSF cells on ECM produced by young cells. Density blots and overlay histograms show the distribution of the M-FSF grown on uncoated plastic (black) or on Y-ECM (grey) based on cell size (FSC-H) granularity (SSC-H) and autofluorescence (FL1-H); data derived from at least 5500 M-FSF.

Further evidence supporting the apparent rejuvenation of M-FSF on Y-ECM was provided by an MTT-based mitochondrial activity and viability assay which showed that M-FSF had a significantly higher viability ( $58 \%$ higher; $\mathrm{p}<0.00001)$ after 9 days of growth on Y-ECM, as compared with the viability of cells grown on plastic (Figure 5). Our observations with normal diploid human skin fibroblasts are in accordance with similar results obtained by other groups working with stem cells that ECM produced in vitro by young cells does provide an environment capable of rejuvenating or improving stem cells $[14,15,23]$. However, it is important to note that the rejuvenation of M-FSF was only partial, and O-FSF did not show any detectable rejuvenation in our studies.

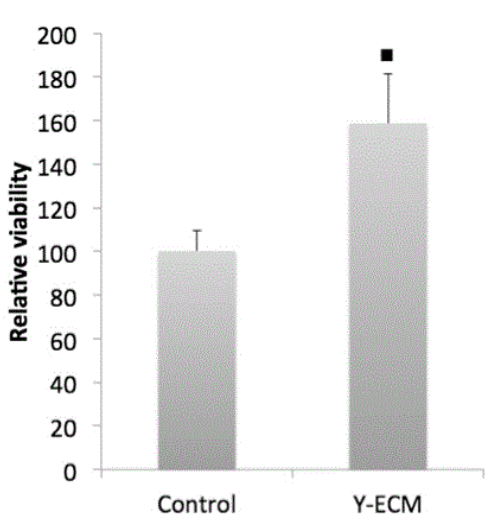

Figure 5: Viability of M-FSF cells grown for 9 days on either YECM or on plastic; $v=p<0.00001$.

\section{Other cellular improvements induced by ECM}

Since we had observed a smoothened morphology and somewhat reduced amounts of lysosomal residual bodies and macromolecular damage-associated autofluorescence in the ECM-cultured cells, we investigated whether Y-ECM would also improve cell viability and stress resistance. Previously, others had shown that ECM could reduce the amount of internal oxidative stress in stem cells and cartilage tissue $[16,24]$. Therefore, we tested the effects of glyoxal (GO), which is known to induce macromolecular damage and premature aging in human cells $[25,26]$, on the viability of Y-FSF grown on either Y-ECM or on uncoated surface.

Figure 6 shows that cells grown on Y-ECM had significantly increased resistance and viability on exposure to the damage-inducing levels of GO. Interestingly, this effect was best seen in cells grown for at least 3 days on Y-ECM, suggesting that the viability-enhancing effects of Y-ECM is a gradual process. One explanation for this could be that freshly trypsinized cells are already stressed to some extent, and exposing them to more stressful conditions may overshadow the protective effects of any other condition until the cells are fully recovered from the stress of trypsinization and reseeding [27]. These observations have profound implications for general cell-culturing as well as for toxicological and aging-modulatory studies, as any change to the cell-splitting and culturing procedures could change the level of stress the cells are exposed to, thus significantly influencing the outcome of the experiments.

Another significant improvement in cellular functionality brought by Y-ECM is the faster rate of cell migration in the wound healing assay. Figure 7 shows that already during the first $24 \mathrm{hr}$, the extent of wound healing in FSF seeded on Y-ECM was 2 times faster than the cells grown on plastic. Although eventually there was a complete healing of the wound by cells on both types of growth surface, ECMgrown cells had significantly faster earlier rate of cell migration and 
proliferation. These sets of observations provide further evidence in support of the results obtained by several other groups reporting that ECM has positive effects on cells in culture [17,23,28].

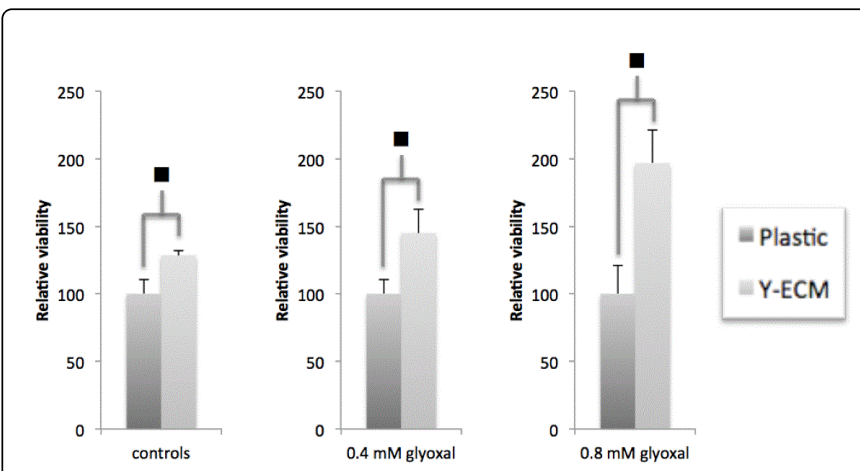

Figure 6: Stress tolerance of Y-FSF cells after exposure to glyoxal when seeded on either plastic or on Y-ECM for 3 days; $n=5$ for each condition, $v=\mathrm{p}<0.01$.

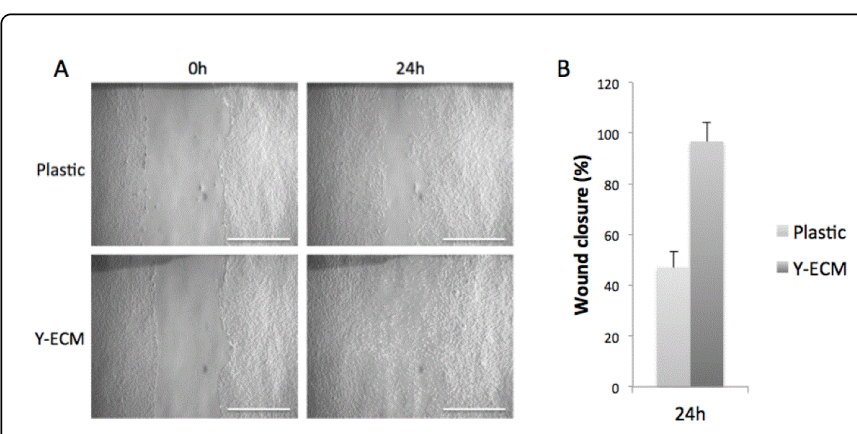

Figure 7: Enhanced wound healing ability of Y-FSF cells seeded on Y-ECM as compared with plastic. (A) Visualization of the wound healing process; phase-contrast microscopic pictures; scale bar $=1000 \mu \mathrm{m}$. (B) Quantification of the extent of wound healing in $24 \mathrm{~h} ; \mathrm{n}=6$ for each condition and time point.

\section{Possible mode of action of ECM by reducing oxidative stress}

It is clear that growing cells on an ECM-coated surface improves several structural and functional aspects of cells, and that this fact should be taken into consideration while investigating the effects of any natural and synthetic compounds on cells in culture. There are several possible modes of action proposed for the role of ECM in improving the quality of life of cultured cells, such as an up regulation of a niche signaling pathway possibly imposing a stem cell state on mature cells [23], through mechanical or biochemical cues [14], and by sequestering and correct presentation of growth factors [16]. Another possibility, which we have investigated here, is that ECM modulates the oxidative stress response of cells, since we had observed that ECM-grown cells had become more tolerant to GO (Figure 6). Using two markers of oxidative stress, Nrf2 and HO-1, our results show that there was a significant decrease ( $65 \%$ and $80 \%$, respectively) in the levels of these stress markers in Y-FSF grown for 3 days on Y-
ECM as compared with the cells grown on uncoated plastic culture flasks (Figure 8). Our further investigations showed that Nrf-2 and HO-1 down regulation was dependent on both the preparation method and the ECM production-time, with methods $4 \mathrm{~b}$ (Y-ECM) and $5 \mathrm{~b}$ (triton-ECM) showing the strongest down regulation (Figure $9 \mathrm{~A}$ and $\mathrm{C}$ ) and with the ECM production-time (Figure 9B and D) correlating well with the amount of Nrf-2 and HO-1 down regulation. Interestingly, even fractured ECM-leftovers provided by trypsinization and mechanical scraping [29] would seemingly protect the cells to some degree. Moreover, ECM was visible within 6 days of production when prepared using method 4 and gave rise to morphological changes similar to ECM produced for 9, 12 and 15 days.

These results demonstrate that ECM-based rejuvenation of senescent cells is not a simple and straightforward process; and it depends on several other variables, such as cell-type differences, type of culture flasks, and method of preparation of ECM. Our investigations suggest that a partial rejuvenation of late passage presenescent cells is possible by growing them on the ECM produced by early passage young cells. Overall, this observation is, to some extent, in line with the previously reported observations [6]. However, the differences in the results obtained in the previous and the present study warrant repeating such experiments using other cell strains and cell types, along with an in depth analysis of a variety of markers of aging, health and functionality of cells.

In conclusion, the results from our study indicate that the ECM and/or the ECM-producing cells provide an environment which is less stressful, making it possible for the aged, as well as the young, cells to protect themselves better for a longer time. This would also suggest that other interventions, which either decrease the internal and external stress for cells, would have beneficial effects. Moreover, these results lend credence to a recently proposed caution that the plastic surface of the cell culture flask creates a layer of reactive oxygen species capable of damaging cells [30-32]. Therefore, it is important to keep in mind the role of ECM and/or the cell-culture surface in modulating the response of cells undergoing aging in vitro while testing potential aging interventions.

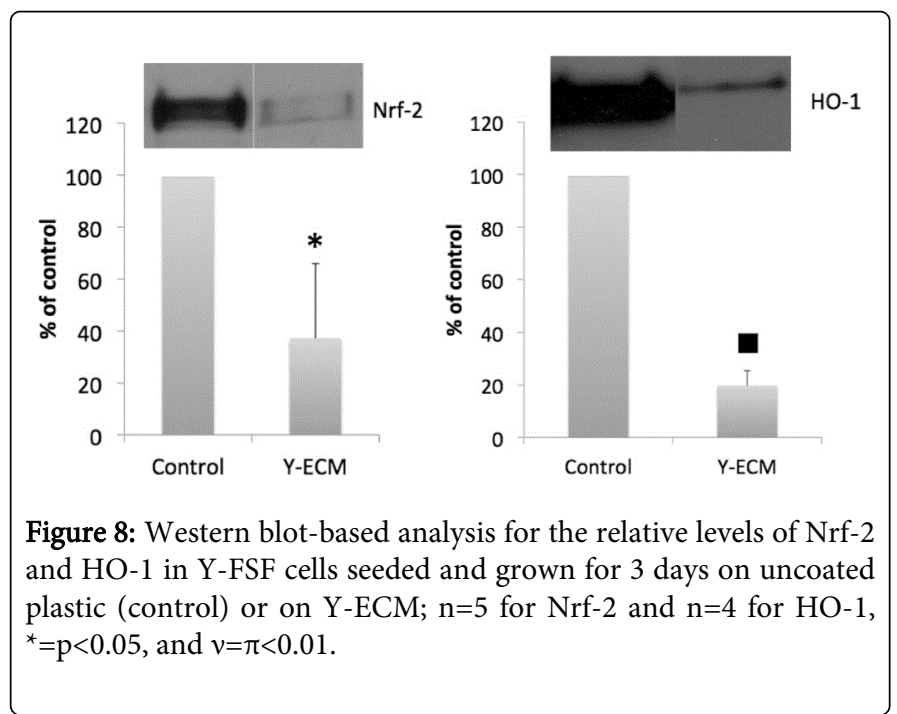


Citation: Joergensen P, Rattan SIS (2014) Extracellular Matrix Modulates Morphology, Growth, Oxidative Stress Response and Functionality of Human Skin Fibroblasts during Aging In Vitro. Aging Sci 2: 122. doi:10.4172/2329-8847.1000122

Page 6 of 7

A

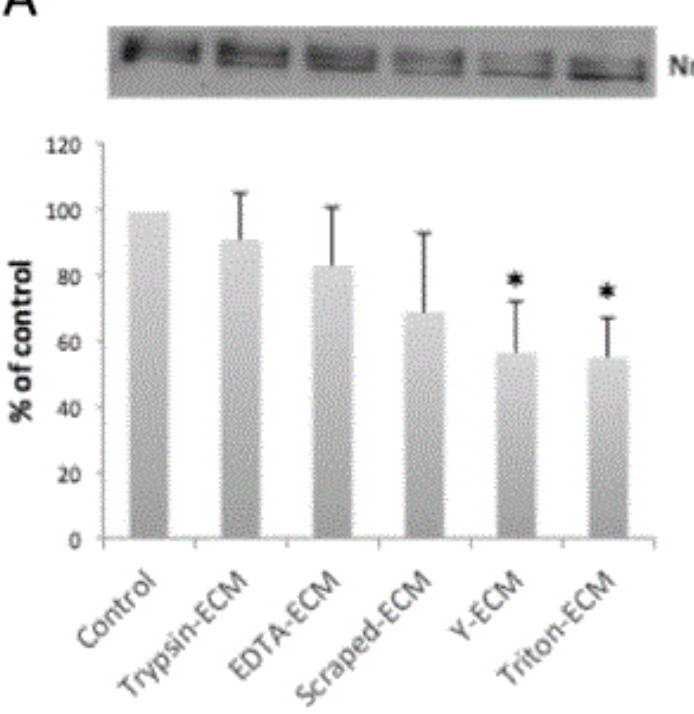

C

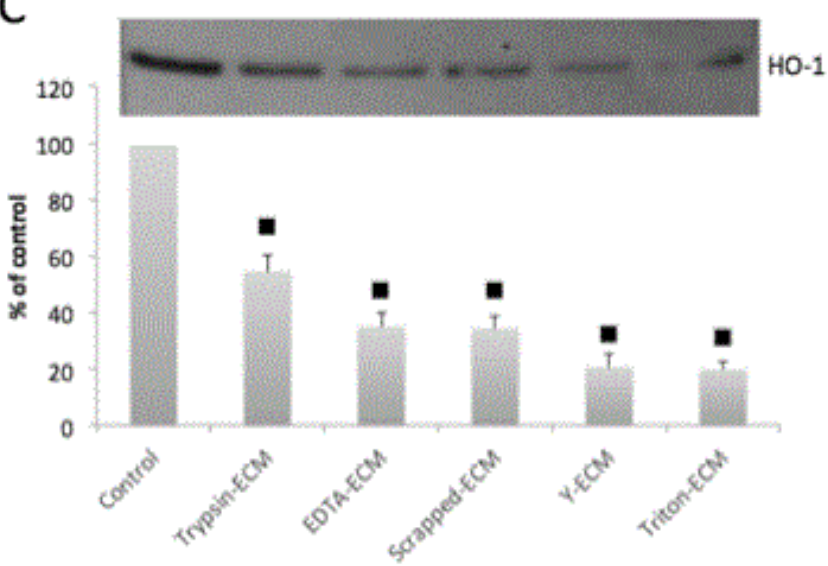

B
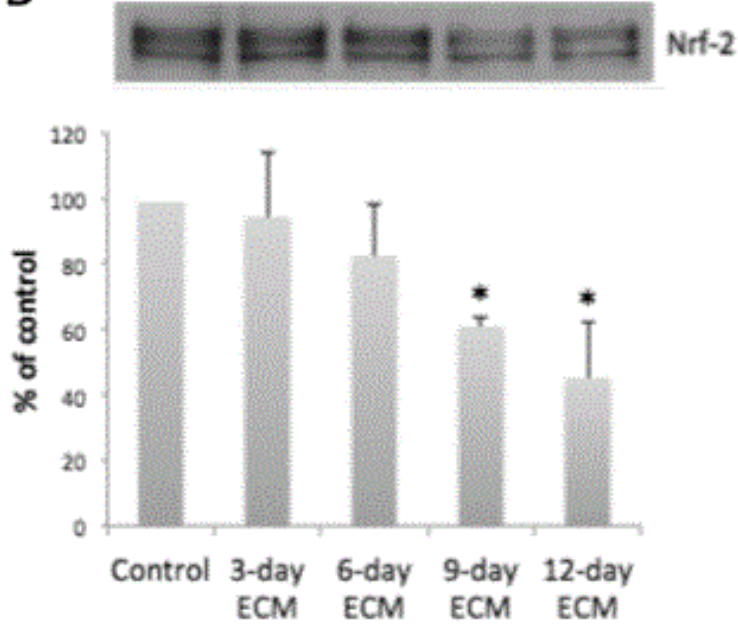

D

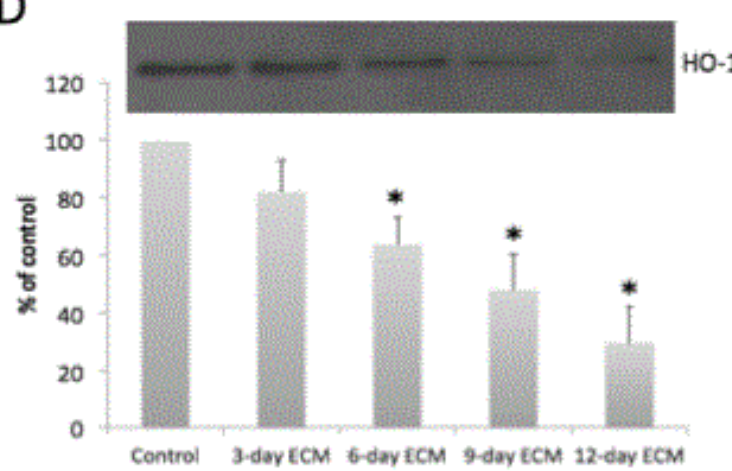

Figure 9: Western blot-based analysis for the relative levels of Nrf-2 (A, B) and HO-1 (C, D), in Y-FSF cells seeded and grown for 3 days on either (A, C) plastic (control), trypsin-ECM, EDTA-ECM, scraped-ECM, Y-ECM or triton-ECM, or (B, D) on ECM produced for different lengths of time; $\mathrm{n}=3$ for all conditions; ${ }^{*}=\mathrm{p}<0.05, v=\mathrm{p}<0.01$.

\section{Acknowledgements}

Laboratory of Cellular Ageing is partially supported by a research grant from LVMH Research, St. Brays, France.

\section{References}

1. Rattan SIS (2012) Cell senescence in vitro. In: eLS. John Wiley \& Sons Ltd, Chichester, UK.

2. Rattan SI, Clark BF (1994) Kinetin delays the onset of ageing characteristics in human fibroblasts. Biochem Biophys Res Commun 201: 665-672.

3. Rattan SI, Sodagam L (2005) Gerontomodulatory and youth-preserving effects of zeatin on human skin fibroblasts undergoing aging in vitro. Rejuvenation Res 8: 46-57.

4. Nizard C, Poggioli S, Heusèle C, Bulteau AL, Moreau M, et al. (2004) Algae extract protection effect on oxidized protein level in human stratum corneum. Ann N Y Acad Sci 1019: 219-222.
5. Widodo N, Shah N, Priyandoko D, Ishii T, Kaul SC, et al. (2009) Deceleration of senescence in normal human fibroblasts by withanone extracted from ashwagandha leaves. The Journals of Gerontology Series A: Biological Sciences and Medical Sciences. 64: 1031-1038.

6. Choi HR, Cho KA, Kang HT, Lee JB, Kaeberlein M, et al. (2011) Restoration of senescent human diploid fibroblasts by modulation of the extracellular matrix. Aging Cell 10: 148-157.

7. Mecham RP (2011) Biology of Extracellular Matrix. Springer 1-441.

8. Lu P, Weaver VM, Werb Z (2012) The extracellular matrix: a dynamic niche in cancer progression. J Cell Biol 196: 395-406.

9. Watt FM, Huck WT (2013) Role of the extracellular matrix in regulating stem cell fate. Nat Rev Mol Cell Biol 14: 467-473.

10. Conboy IM, Conboy MJ, Wagers AJ, Girma ER, Weissman IL, et al. (2005) Rejuvenation of aged progenitor cells by exposure to a young systemic environment. Nature 433: 760-764.

11. Giguère L, Cheng J, Gospodarowicz D (1982) Factors involved in the control of proliferation of bovine corneal endothelial cells maintained in serum-free medium. J Cell Physiol 110: 72-80. 
Citation: Joergensen P, Rattan SIS (2014) Extracellular Matrix Modulates Morphology, Growth, Oxidative Stress Response and Functionality of Human Skin Fibroblasts during Aging In Vitro. Aging Sci 2: 122. doi:10.4172/2329-8847.1000122

Page 7 of 7

12. Song MK, Lui GM (1990) Propagation of fetal human RPE cells: preservation of original culture morphology after serial passage. J Cell Physiol 143: 196-203.

13. Li J, He F, Pei M (2011) Creation of an in vitro microenvironment to enhance human fetal synovium-derived stem cell chondrogenesis. Cell Tissue Res 345: 357-365.

14. He F, Chen X, Pei M (2009) Reconstruction of an in vitro tissue-specific microenvironment to rejuvenate synovium-derived stem cells for cartilage tissue engineering. Tissue Eng Part A 15: 3809-3821.

15. Sun Y, Li W, Lu Z, Chen R, Ling J, et al. (2011) Rescuing replication and osteogenesis of aged mesenchymal stem cells by exposure to a young extracellular matrix. FASEB J 25: 1474-1485.

16. Lai Y, Sun Y, Skinner CM, Son EL, Lu Z, et al. (2010) Reconstitution of Marrow-Derived Extracellular Matrix Ex Vivo: A Robust Culture System for Expanding Large-Scale Highly Functional Human Mesenchymal Stem Cells. Stem Cells Dev 19: 1095-1107.

17. Chen X, Dusevich V, Feng JQ, Manolagas SC, Jilka RL (2007) Extracellular matrix made by bone marrow cells facilitates expansion of marrow-derived mesenchymal progenitor cells and prevents their differentiation into osteoblasts. J Bone Miner Res 22: 1943-1956.

18. Jørgensen P, Milkovic L, Zarkovic N, Waeg G, Rattan SIS (2014) Lipid peroxidation-derived 4-hydroxynonenal-modified proteins accumulate in human facial skin fibroblasts during ageing in vitro. Biogerontology 15: $105-110$

19. Demirovic D, Rattan SI (2011) Curcumin induces stress response and hormetically modulates wound healing ability of human skin fibroblasts undergoing ageing in vitro. Biogerontology 12: 437-444.

20. Hakkinen KM, Harunaga JS, Doyle AD, Yamada KM (2011) Direct comparisons of the morphology, migration, cell adhesions, and actin cytoskeleton of fibroblasts in four different three-dimensional extracellular matrices. Tissue Eng Part A 17: 713-724.

21. Kurtz A, Oh SJ (2012) Age related changes of the extracellular matrix and stem cell maintenance. Prev Med 54 Suppl: S50-56.
22. Rattan SIS (2010) Aging of skin cells in culture. In: Textbook of Aging Skin. Springer, New York 487-492.

23. He F, Pei M (2012) Rejuvenation of nucleus pulposus cells using extracellular matrix deposited by synovium-derived stem cells. Spine (Phila Pa 1976) 37: 459-469.

24. Pei M, Li JT, Shoukry M, Zhang Y (2011) A review of decellularized stem cell matrix: a novel cell expansion system for cartilage tissue engineering. Eur Cell Mater 22: 333-343.

25. Sejersen H, Rattan SI (2007) Glyoxal-induced premature senescence in human fibroblasts. Ann N Y Acad Sci 1100: 518-523.

26. Larsen SA, Kassem M, Rattan SI (2012) Glucose metabolite glyoxal induces senescence in telomerase-immortalized human mesenchymal stem cells. Chem Cent J 6: 18.

27. Huang HL, Hsing HW, Lai TC, Chen YW, Lee TR, et al. (2010) Trypsininduced proteome alteration during cell subculture in mammalian cells. J Biomed Sci 17: 36 .

28. Fan G, Wen L, Li M, Li C, Luo B, et al. (2011) Isolation of mouse mesenchymal stem cells with normal ploidy from bone marrows by reducing oxidative stress in combination with extracellular matrix. BMC Cell Biol 12: 30 .

29. Canavan HE, Cheng X, Graham DJ, Ratner BD, Castner DG (2005) Cell sheet detachment affects the extracellular matrix: A surface science study comparing thermal liftoff, enzymatic, and mechanical methods. J Biomed Mater Res 75: 1-13.

30. Sommer AP, Lotan N (2010) Controls needed to reduce problem of plastic contamination. Nature 465: 289.

31. Sommer AP, Haddad MK, Fecht H-J (2012) It is time for a change: Petri dishes weaken cells. J Bionic Engin 9: 353-357.

32. Sommer AP, Zhu D, Gagsteiger F, Fecht H-J (2013) Sperm Performance Better on Diamond than on Polystyrene. MRS Proc 1511. 